\title{
Multimaterial and multicolor 3D-printed model in training of transnasal endoscopic surgery for pituitary adenoma
}

\author{
Jia-Ping Zheng, MD, ${ }^{1}$ Chu-Zhong Li, MD, ${ }^{2}$ and Guo-Qiang Chen, MD' \\ 'Department of Neurosurgery, Aviation General Hospital, Beijing; and Beijing Neurosurgical Institute, Beijing Tiantan Hospital, \\ Capital Medical University, Beijing, China
}

\begin{abstract}
OBJECTIVE The aim of the present study was to investigate the practical value of a multimaterial and multicolor 3Dprinted model in anatomical teaching, surgical training, and preoperative planning of transnasal endoscopic surgery for pituitary adenoma.

METHODS Multimodality neuroimaging data were obtained in a 42-year-old healthy male volunteer and a 40-year-old female patient with an invasive nonfunctional pituitary adenoma. Three 3D-printed models were produced: a monomaterial and monocolor model, a monomaterial and multicolor model, and a multimaterial and multicolor model. The effects on anatomical teaching and surgical training for exposing the vidian nerve were assessed by 12 residents, and the training effect was validated on cadavers. The practical values for preoperative planning were evaluated by 6 experienced neurosurgeons. All evaluations were based on 5-point Likert questionnaires.
\end{abstract}

RESULTS The multimaterial and multicolor model was superior to the monomaterial models in surgical training for exposing the vidian nerve (Fisher test; $p<0.05$ ). In addition, the multimaterial and multicolor model was superior to the monomaterial models in anatomical teaching and preoperative planning (Friedman test; $p<0.05$ ).

CONCLUSIONS Multimaterial and multicolor 3D printing technology makes it convenient and efficient to produce a practical model for simulating individualized and complex anatomical structures in the sellar region. Furthermore, the multimaterial model can provide a more realistic manipulative experience for surgical training and facilitate the preoperative planning.

https://thejns.org/doi/abs/10.3171/2019.6.FOCUS19294

KEYWORDS pituitary adenoma; transnasal endoscopic surgery; anatomical teaching; 3D-printed model; multimaterial printed model; surgical training; multimodality neuroimaging

$\mathrm{P}$ ITUITARY adenomas are common tumors that occur in the pituitary gland. The mainstay of treatment for pituitary adenomas is resection. Furthermore, endoscopic endonasal transsphenoidal surgery (EETSS) has been widely used as a safe approach. EETSS provides a clearer surgical panoramic view, and allows for a more complete tumor removal. ${ }^{5,6,8,12}$ However, transnasal endoscopic surgery has a steep learning curve, and young neurosurgeons face great challenges. ${ }^{4,21}$ The lack of a convenient and practical model for anatomical learning and surgical training limits the development of EETSS., ${ }^{3,11,17}$

There are many reports regarding skull base models for neurosurgical training. ${ }^{1,15,24}$ According to a previous study, individualized models that reflect the anatomical relationship between the tumor and surrounding structures can effectively avoid surgical complications and shorten operation time.${ }^{14}$ However, due to the limitation of craftsmanship, 3D-printed models that are made of hard materials cannot provide realistic tactile feedback. ${ }^{25}$ The popularity of multicolor, multimaterial 3D printing technology allows its use for the production of a more high-fidelity model that reproduces blood vessels, nerves, bones, and tumors. ${ }^{23,25}$

In the present study, multimodality neuroimaging data were collected and skull base models were produced using $3 \mathrm{D}$ printing technology. Then, the practical values of 3Dprinted models in the anatomical teaching, surgical train-

ABBREVIATIONS EETSS = endoscopic endonasal transsphenoidal surgery; ICA = internal carotid artery; SCA = superior cerebellar artery; STL = stereolithography. SUBMITTED April 11, 2019. ACCEPTED June 6, 2019.

INCLUDE WHEN CITING DOI: 10.3171/2019.6.FOCUS19294. 

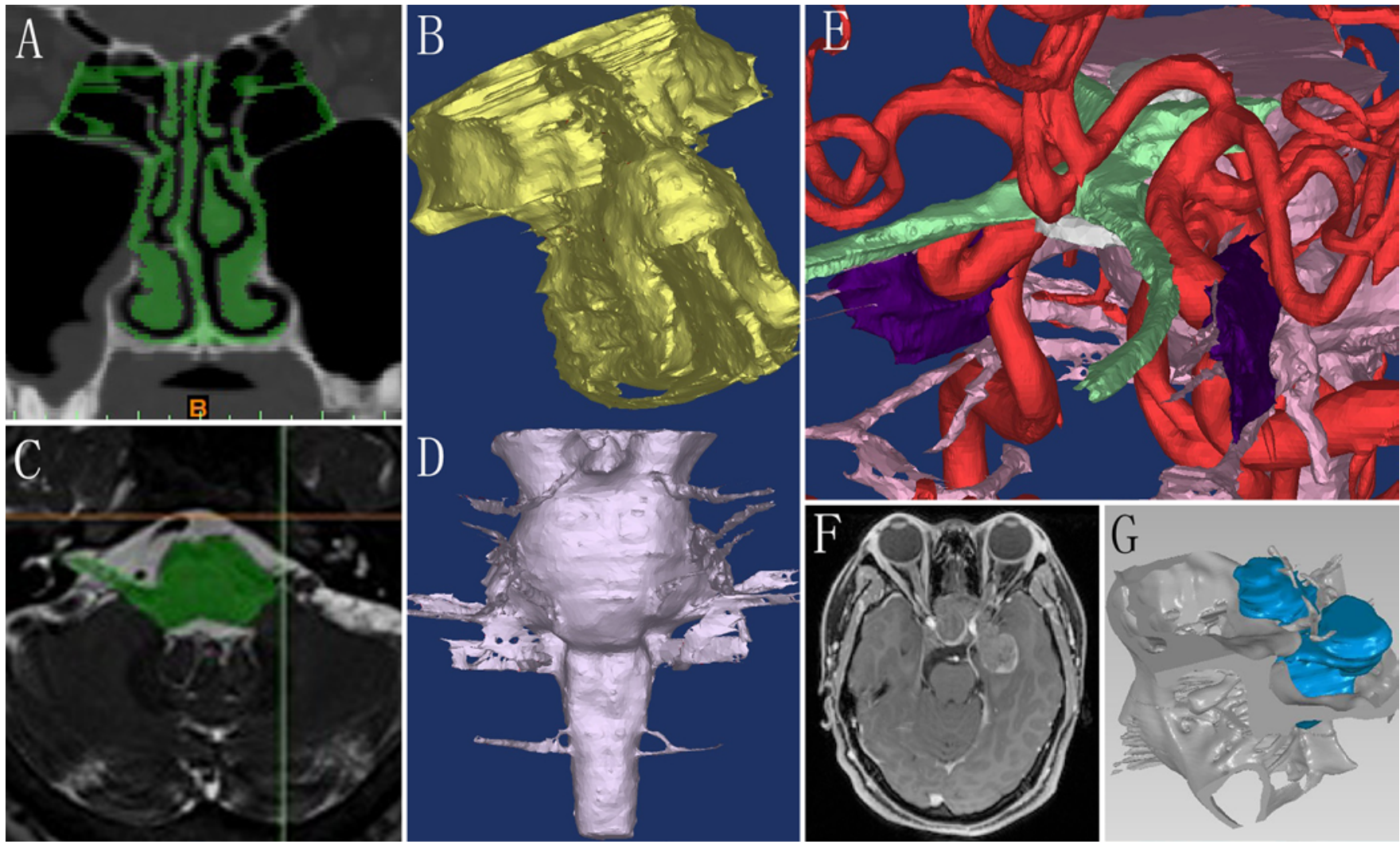

FIG. 1. Imaging data processing. A: The turbinate was manually delineated from the surrounding structures. B: The 3D paranasal sinus model was reconstructed. C: The brainstem and cranial nerves were manually delineated from the surrounding structures. D: The 3D brainstem and cranial nerve models were reconstructed. E: The space coordinates of the blood vessels and nerves were aligned. F: The axial T1-weighted MRI of the patient with invasive pituitary adenoma. G: The 3D model was delineated using the computer-aided design software, and the printed model was installed on a pedestal (Geomagic 3D Systems).

ing, and preoperative planning of transnasal endoscopic surgery for pituitary adenoma were investigated.

\section{Methods \\ Collection of Imaging Data}

Multimodality neuroimaging data were obtained in a 42-year-old healthy male volunteer and a 40-year-old female patient with invasive nonfunctional pituitary adenoma. MRI was performed using a 3-T scanner (General Electric, Inc.). The sequences included routine T1-weighted and T2-weighted imaging and magnetic resonance angiography (MRA). After gadolinium-diethylenetriamine pentaacetic acid (Gd-DTPA) administration, 3D fast imaging employing steady-state acquisition (3D-FIESTA) imaging was obtained. CT was performed using a 128row multidetector CT scanner (General Electric, Inc.) with a slice thickness of $0.3 \mathrm{~mm}$.

\section{Data Processing}

The Digital Imaging and Communications in Medicine (DICOM) imaging data were processed using Mimics software (Materialise). The 3D modeling data were saved as an STL (stereolithography) file (Fig. 1).

\section{Model Printing}

The processed STL file was imported into a multimaterial (MultiJet) 3D printer (Objet J750 Connex; Stratasys). Three 3D-printed models were produced: a monomaterial and monocolor model, a monomaterial and multicolor model, and a multimaterial and multicolor model (Fig. 2).

\section{Assessment of Practical Value}

The practical values of the models for surgical training were assessed by 12 residents. These residents were randomly divided into 3 groups (4 in each group), and each group assessed 1 of the 3 models. The residents used an endoscopic and surgical drill to expose the vidian nerve on the models (Fig. 3E-G). Each resident repeated the procedures 4 times, and the success rate for completely exposing the vidian nerve was recorded. Then, the training effect was validated on cadavers. Each resident was required to expose the vidian nerve on 2 cadavers (Fig. $3 \mathrm{H}$ ), and the success rate for completely exposing the vidian nerve was recorded.

For anatomical teaching, 12 residents used the 3Dprinted models to learn the important anatomical structures (Figs. 3 and 4). Then, the teaching effect was evaluated using a 5-point Likert scale (from $1=$ strongly disagree to $5=$ strongly agree). 

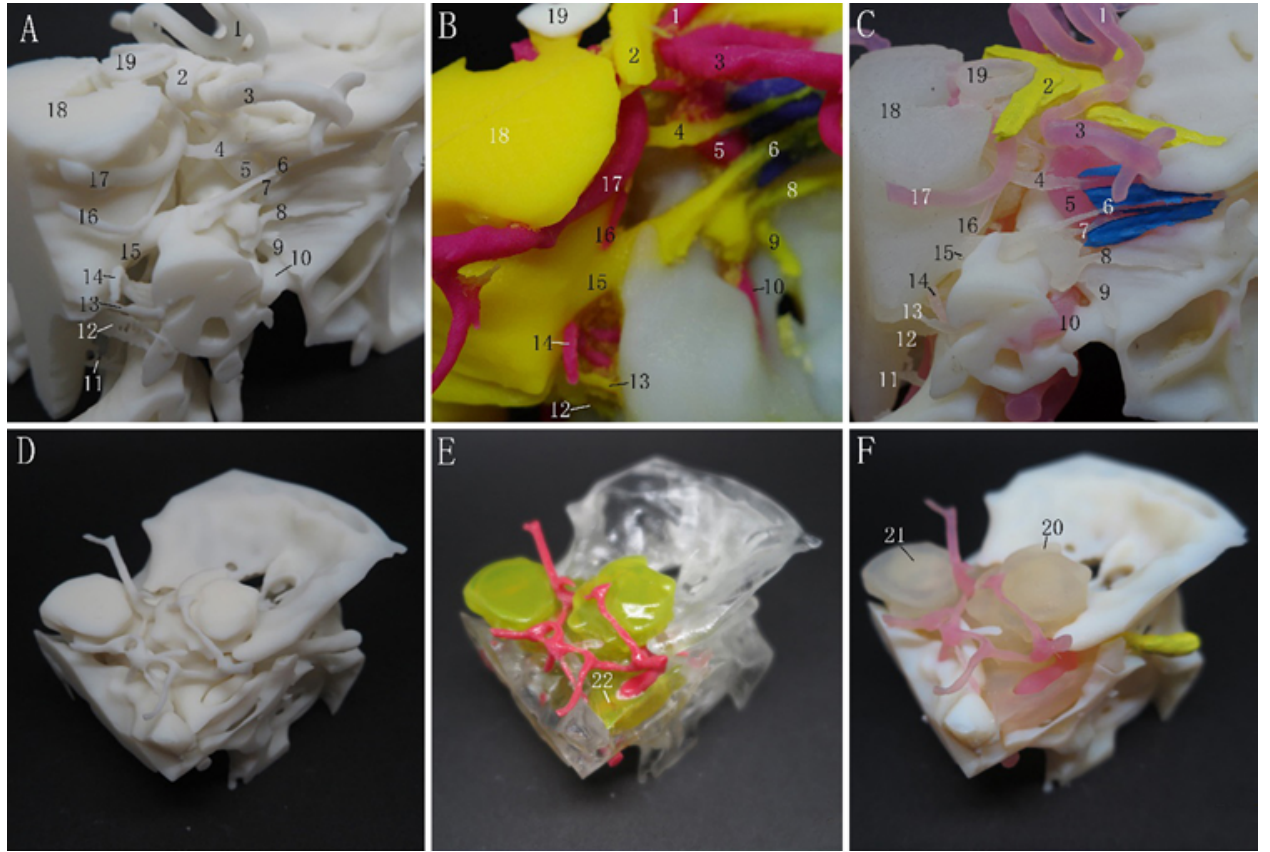

FIG. 2. Printed models made of different materials. A: The monocolor and monomaterial skull base model. B: The multicolor and monomaterial skull base model. C: The multicolor and multimaterial skull base model. D: The monocolor and monomaterial model simulating the invasive pituitary adenoma. E: The multicolor and monomaterial model simulating the invasive pituitary adenoma. F: The multicolor and multimaterial model simulating the invasive pituitary adenoma. Key structures: 1, anterior cerebral artery; 2, optic chiasma; 3 , middle cerebral artery; 4 , oculomotor nerve; 5 , siphon segment of the ICA; 6 , abducens nerve; 7 , ophthalmic branch of trigeminal nerve; 8 , maxillary branch of trigeminal nerve; 9 , mandibular branch of trigeminal nerve; 10 , petrosal segment of the ICA; 11, hypoglossal nerve; 12 , vagus nerve and glossopharyngeal nerve; 13 , facial nerve and auditory nerve; 14 , anterior inferior cerebellar artery; 15, trigeminal nerve; 16, superior cerebellar artery (SCA); 17, posterior cerebral artery; 18, mesencephalon; 19, hypothalamus; 20 , the tumor was printed as a hollow structure with a 2 -mm wall; 21 , the shell is transparent and the internal supporting material is visible; 22, the tumor is made of a transparent material, and the wrapped ICA is visible.

The practical values for preoperative planning were evaluated by 6 experienced neurosurgeons (Fig. 5), and the planning was compared with the actual surgical procedures in the video. The effect on the preoperative planning was evaluated using a 5-point Likert scale.

\section{Statistical Analysis}

SPSS 25.0 software (IBM Corp.) was used for statistical analyses. The success rates for completely exposing the vidian nerve using different models or cadavers were compared using Fisher's test. Comparisons among the multimaterial, multicolor model and the 2 monomaterial models were performed using the Friedman test. Probability values of $\leq 0.05$ were considered statistically significant.

\section{Results}

The success rates for completely exposing the vidian nerve on the monomaterial and monocolor model, monomaterial and multicolor model, and multimaterial and multicolor model were $6.67 \%, 31.25 \%$, and $75.00 \%$, respectively. The Fisher test revealed the success rate in the multimaterial and multicolor model group, which was significantly superior when compared to the other 2 groups $(\mathrm{p}<0.05)$. On the cadavers, the success rate for complete exposure of the vidian nerve in the group trained with the monomaterial and monocolor model was $18.75 \%$, the success rate in the group trained with the monomaterial and multicolor model was $37.50 \%$, and the success rate in the group trained with the multimaterial and multicolor model was $81.25 \%$. The Fisher test revealed that the success rate in the multimaterial and multicolor model group was significantly superior to that in the other 2 groups $(\mathrm{p}<0.05)$.

The anatomical teaching effects of these 3 skull base models are summarized in Table 1 . The Friedman test revealed that the learning effects of the multimaterial and multicolor model were significantly superior to those of the monomaterial models $(\mathrm{p}<0.01)$.

The practical values of these 3 skull base models for preoperative planning are summarized in Table 2. The Friedman test revealed that the practical values of the multimaterial and multicolor model were significantly superior to those of the monomaterial models $(\mathrm{p}<0.01)$. The monomaterial and multicolor model was made of a transparent, hard resin material (Fig. 2E), which was helpful for learning the anatomical relationship between the tumor and surrounding structures. The monomaterial and monocolor model can only be used for the observation of partial morphology of the tumor. The multimaterial and multicolor model can be used to simulate the endoscopic procedures: the elastic turbinate and nasal septum can be easily removed (Fig. 5A); after removing the anterior wall of the sphenoid sinus, the tumor can be exposed (Fig. 5B); 


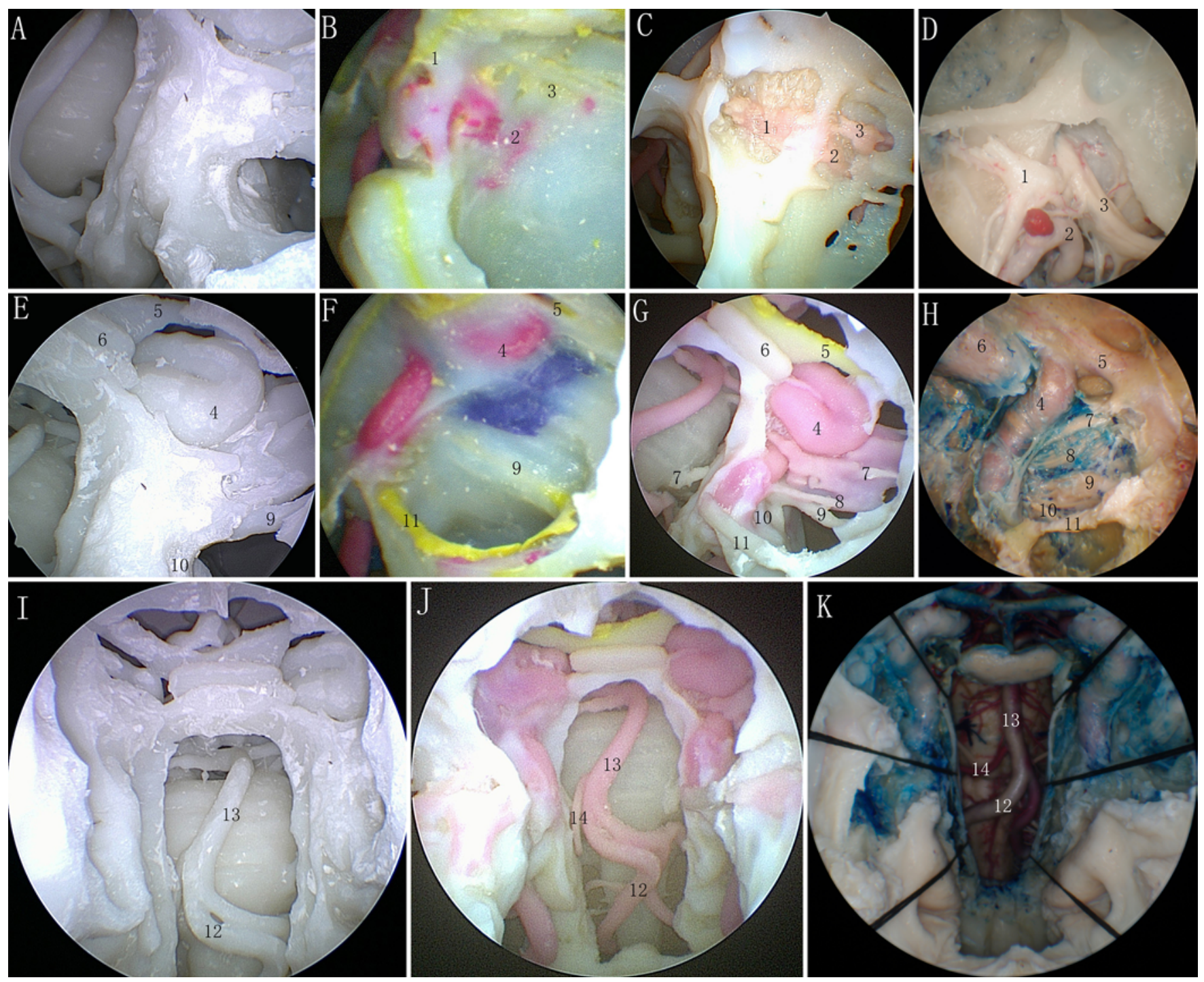

FIG. 3. Local structures. A, E, and I: The monocolor and monomaterial model is used for anatomical teaching in which the vessels and nerves can be distinguished according to the structure contours. B and F: The multicolor and monomaterial model is used for anatomical teaching in which the vessels and nerves can be distinguished according to color differences, but there is no interstructure boundary. C, G, and J: The multicolor and multimaterial model is used for anatomical teaching in which the vessels and nerves can be easily distinguished according to different color and hardness, and the interstructure boundary is clear. D, H, and K: The pterygopalatine fossa, cavernous sinus, and basilar artery were observed in the cadaver. Key structures: $1, C_{2}$ segment of the ICA; 2, cavernous sinus; 3 , optic nerve; 4, trigeminal ganglion; 5 , maxillary nerve; 6 , mandibular nerve; 7 , oculomotor nerve; 8 , trigeminal nerve; 9 , facial and auditory nerve; 10 , vagus nerve; 11 , hypoglossal nerve; 12 , anterior cerebral artery; 13 , middle cerebral artery; 14, posterior cerebral artery.

the internal carotid artery (ICA) can be observed in an endoscopic view (Fig. 5C).

\section{Discussion}

Conventional skull base models have significant limitations. The craftsmanship is ineffective, and it is difficult to make individualized models. ${ }^{7,13}$ Compared with monomaterial skull base models, the multicolor and multimaterial model has more abundant anatomical details. ${ }^{25}$ The simultaneous printing of soft and hard structures makes the production of a nasal cavity simulator simpler than previ- ously reported methods. ${ }^{2,14}$ Stratasys $\mathrm{J} 750$ is an advanced MultiJet printing device that has a 14-micron precision per layer, and it can be filled with 6 materials of different colors and hardness. Compared with previous multimaterial models ${ }^{18}$ these new 3D-printed models can reproduce complex structures in the skull base.

\section{Application of Multimaterial 3D-Printed Models in EETSS- Related Anatomy Learning}

Five materials of different colors and hardness were used to reflect the complex anatomical structures in the 

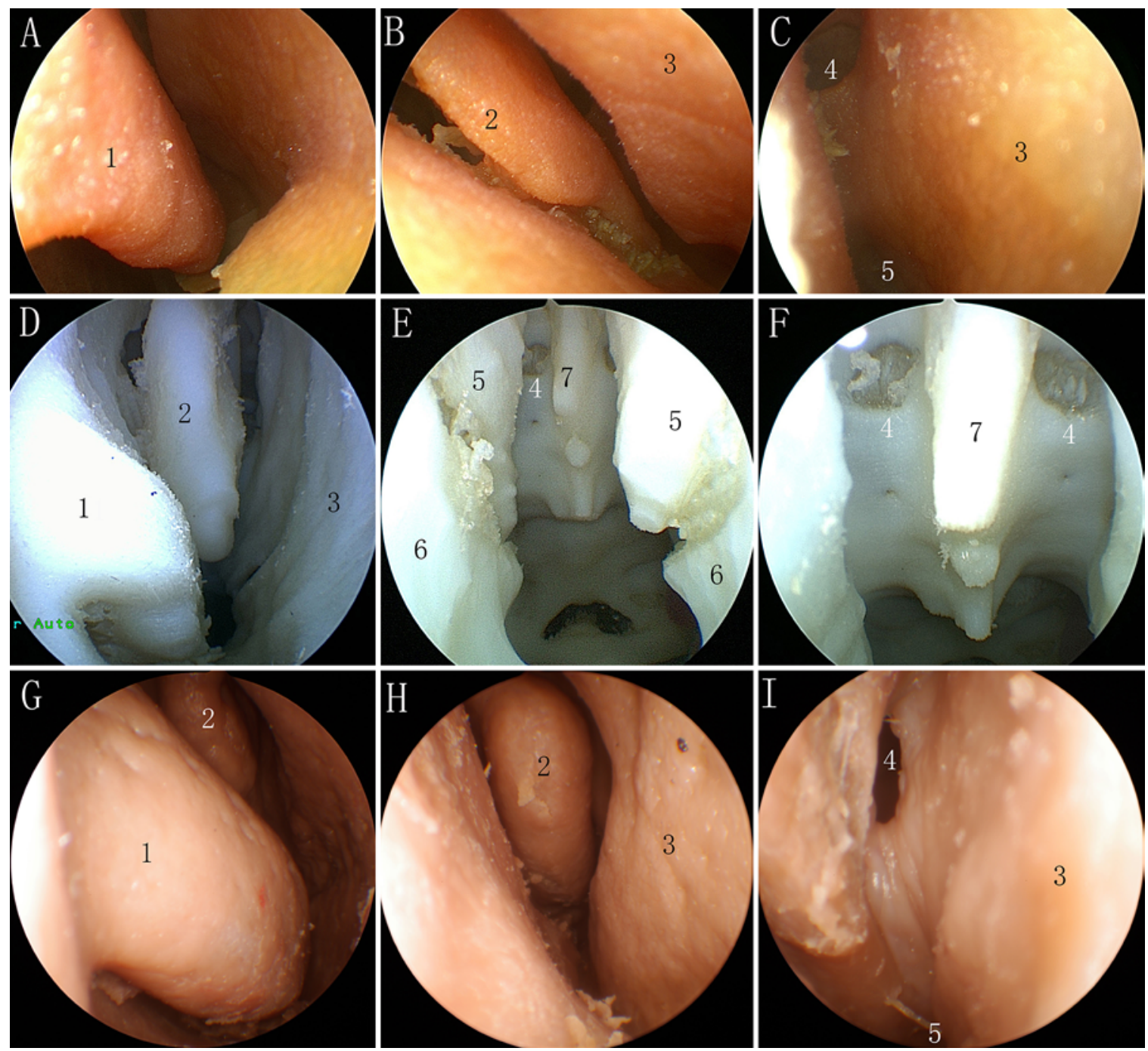

FIG. 4. Endoscopic views. A-C: The multicolor and multimaterial model provides a realistic color and tactile feedback, and the rubber-like resin is elastic. D-F: The turbinate is hard in the monomaterial models, and the exposure of the sphenoid sinus needs a grinding drill, which is distinct from the true procedures. G-I: Structures within the cadaver nasal cavity are shown. Key structures: 1 , inferior turbinate; 2 , middle turbinate; 3 , nasal septum; 4, opening of sphenoid sinus; 5 , postnaris; 6 , uncinate process; 7 , perpendicular plate of the ethmoid.

skull base, including blood vessels, nerves, and fine bone structures. Soft materials provide a realistic tactile feedback, which is conducive to understanding the morphological and positional relationships of anatomical structures (Fig. 3). Thus, trainees can get a realistic experience of operation within the nasal cavity (Fig. 4).

The vidian nerve is located between the pterygopalatine fossa and anterior genu of the ICA, which is a crucial landmark for locating the petrosal segment of the ICA. In addition, the intraoperative preservation of the vidian nerve is important to maintain the function of tear secretion..$^{9,16,22}$

The localization and exposure of the vidian nerve remains a challenge for young surgeons, and that is the reason why complete exposure of the vidian nerve was chosen as the training goal. Because there are differences in color and hardness, the exposure of the vidian nerve in the multicolor multimaterial model would be realistic.

\section{Application of Multimaterial 3D-Printed Models in Preoperative Planning}

Hard-resin models cannot simulate the true texture of the tumor and its surrounding structures..$^{10,19,20}$ In our experience, the supporting materials used by the Objet J750 printer are soft, moist, ivory-colored, waxy, semisolid materials that can be removed using forceps and curettes. The printed tumor is filled with a soft supporting material with a rubber-like resinous shell. The tumor is wrapped around the ICA, mimicking the anatomical characteristics of an invasive pituitary tumor. The multimaterial 3D-printed model can help trainees understand the spatial relationship of anatomical structures under an endoscopic view. 

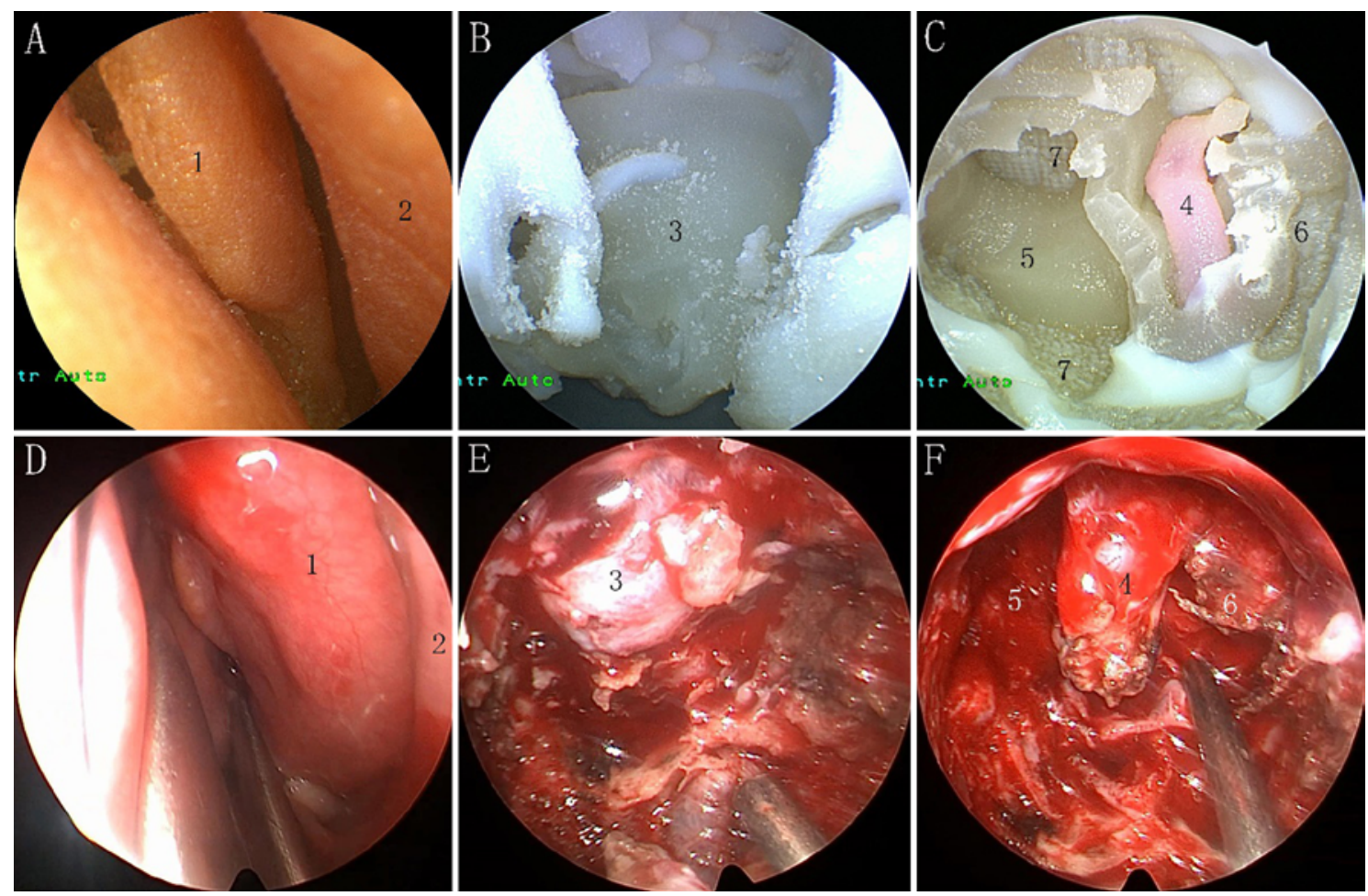

FIG. 5. Comparison of model training and actual procedures. A-C: On the model, the soft wall of the tumor can be removed using a bistoury, and the ICA is visible after removing the soft supporting materials. D-F: The corresponding views in the actual operation are shown. Key structures: 1, left middle turbinate; 2, nasal septum; 3, dura mater in the bottom of the saddle; 4, cavernous sinus segment of the left ICA; 5 , tumor cavity; 6 , tumor involving the cavernous sinus; 7 , supporting materials.

TABLE 1. Learning effects of the 3 skull base models

\begin{tabular}{|c|c|c|c|}
\hline \multirow[b]{2}{*}{ Items Scored } & \multicolumn{3}{|c|}{ Likert Score } \\
\hline & $\begin{array}{l}\text { Multimaterial, } \\
\text { Multicolor } \\
\text { Model }\end{array}$ & $\begin{array}{l}\text { Monomaterial, } \\
\text { Multicolor } \\
\text { Model }\end{array}$ & $\begin{array}{c}\text { Monomaterial, } \\
\text { Monocolor } \\
\text { Model }\end{array}$ \\
\hline The model can help me understand the structures and spatial locations of paranasal sinuses. & 4.1 & 3.9 & 3.9 \\
\hline Learning to use the model is more effective than learning on a computer. & 5 & 4 & 3 \\
\hline The model can help me understand the anatomical structures of the lateral nasal wall. & 4.9 & 3.1 & 3.1 \\
\hline The model can help me understand the anatomical structures of the vidian nerve. & 4.9 & 3.5 & 1.5 \\
\hline The model can help me understand the anatomical structures of the Meckel sac. & 4.8 & 4.2 & 4.2 \\
\hline $\begin{array}{l}\text { The model can help me understand the anatomical structures of the sphenoid sinus (opening of the } \\
\text { sphenoid sinus, canalis opticus, apophysis of the ICA, and apophysis of the saddle bottom). }\end{array}$ & 4.9 & 4.6 & 4.6 \\
\hline The model can help me understand the anatomical structures of the pterygopalatine fossa. & 4.7 & 4.2 & 1.5 \\
\hline $\begin{array}{l}\text { The model can help me understand the anatomical structures of the ethmoid sinus (ethmoidal bulb } \\
\text { and diapophysis). }\end{array}$ & 4.7 & 4.5 & 4.5 \\
\hline The model can help me understand the anatomical structures of the cavernous sinus. & 4.7 & 4 & 1.4 \\
\hline The model can help me understand the anatomical structures of the ICA. & 4.9 & 4.5 & 2.8 \\
\hline The model can help me understand the anatomical structures of the abducens nerve. & 4.9 & 4.2 & 3.8 \\
\hline The model can help me understand the anatomical structures of the craniocervical junction. & 3.9 & 3.9 & 3.6 \\
\hline The model can help me understand the anatomical structures of the clivus. & 4.6 & 4 & 3.4 \\
\hline The model can help me improve my hand-eye coordination. & 4.6 & 4.3 & 4.3 \\
\hline The model can help me improve my operative skills in using endoscopic instruments. & 4.6 & 3.8 & 4.4 \\
\hline The model can help me adapt the operative views of the extended transnasal approach. & 4.6 & 4.4 & 4.4 \\
\hline The model can help me improve my proficiency using a surgical grinder. & 4.8 & 3.9 & 3.7 \\
\hline The model can help me improve the learning effect on the cadavers. & 4.6 & 4.2 & 3.2 \\
\hline
\end{tabular}

Definitions of scores for 5-point Likert scale: 1, Strongly Disagree; 2, Disagree; 3, Neutral; 4, Agree; 5, Strongly Agree. The Friedman test revealed that the learning effects of the multimaterial and multicolor model were significantly superior to those of the monomaterial models $(p<0.01)$. 


\begin{tabular}{llcc}
\hline \multicolumn{1}{c}{ Items Scored } & \multicolumn{2}{c}{ Likert Score } \\
\cline { 2 - 4 } & $\begin{array}{c}\text { Multimaterial, } \\
\text { Multicolor Model }\end{array}$ & $\begin{array}{c}\text { Monomaterial, } \\
\text { Multicolor } \\
\text { Model }\end{array}$ & $\begin{array}{c}\text { Monomaterial, } \\
\text { Monocolor Model }\end{array}$ \\
\hline Total effects & 4.7 & 4 & 1.4 \\
\hline Morphology of the tumor & 5 & 4 & 2.4 \\
\hline Spatial location of the tumor & 4.7 & 4 & 3 \\
\hline Anatomical relationship between the tumor and ICA & 5 & 4 & 1.4 \\
\hline Texture of the tumor & 1 & 1 & 1 \\
\hline Anatomical relationship between the tumor and sphenoid sinus & 4.5 & 2.1 & 1 \\
\hline Anatomical relationship between the tumor and cavernous sinus & 1 & 1 & 1 \\
\hline Superior to 2D imaging & 4.7 & 4.5 & 2 \\
\hline Superior to 3D visual models & 4.3 & 3.2 & 1 \\
\hline Practicability & 4.3 & 3 & 1 \\
\hline
\end{tabular}

The Friedman test revealed that the practical values of the multimaterial and multicolor model were significantly superior to those of the monomaterial models $(p<0.01)$.

\section{Conclusions}

Multimaterial multicolor 3D printing technology makes it convenient and efficient to produce a practical model for simulating individualized and complex anatomical structures in the sellar region. The multimaterial model can provide a more realistic manipulative experience for surgical training, and facilitate the preoperative planning for the resection of pituitary adenomas.

\section{References}

1. Berhouma M, Baidya NB, Ismaïl AA, Zhang J, Ammirati M: Shortening the learning curve in endoscopic endonasal skull base surgery: a reproducible polymer tumor model for the trans-sphenoidal trans-tubercular approach to retro-infundibular tumors. Clin Neurol Neurosurg 115:1635-1641, 2013

2. Chan HH, Siewerdsen JH, Vescan A, Daly MJ, Prisman E, Irish JC: 3D rapid prototyping for otolaryngology-head and neck surgery: applications in image-guidance, surgical simulation and patient-specific modeling. PLoS One 10:e0136370, 2015

3. Chi F, Wang Y, Lin Y, Ge J, Qiu Y, Guo L: A learning curve of endoscopic transsphenoidal surgery for pituitary adenoma. J Craniofac Surg 24:2064-2067, 2013

4. Chin OY, Ghosh R, Fang CH, Baredes S, Liu JK, Eloy JA: Internal carotid artery injury in endoscopic endonasal surgery: a systematic review. Laryngoscope 126:582-590, 2016

5. Dhandapani S, Singh H, Negm HM, Cohen S, Anand VK, Schwartz TH: Cavernous sinus invasion in pituitary adenomas: systematic review and pooled data meta-analysis of radiologic criteria and comparison of endoscopic and microscopic surgery. World Neurosurg 96:36-46, 2016

6. Gondim JA, Almeida JP, Albuquerque LA, Gomes EF, Schops M: Giant pituitary adenomas: surgical outcomes of 50 cases operated on by the endonasal endoscopic approach. World Neurosurg 82:e281-e290, 2014

7. Hochman JB, Kraut J, Kazmerik K, Unger BJ: Generation of a $3 \mathrm{D}$ printed temporal bone model with internal fidelity and validation of the mechanical construct. Otolaryngol Head Neck Surg 150:448-454, 2014

8. Juraschka K, Khan OH, Godoy BL, Monsalves E, Kilian A, Krischek B, et al: Endoscopic endonasal transsphenoidal ap- proach to large and giant pituitary adenomas: institutional experience and predictors of extent of resection. J Neurosurg 121:75-83, 2014

9. Kassam AB, Vescan AD, Carrau RL, Prevedello DM, Gardner P, Mintz AH, et al: Expanded endonasal approach: vidian canal as a landmark to the petrous internal carotid artery. $\mathbf{J}$ Neurosurg 108:177-183, 2008

10. Lan Q, Chen A, Zhang T, Li G, Zhu Q, Fan X, et al: Development of three-dimensional printed craniocerebral models for simulated neurosurgery. World Neurosurg 91:434-442, 2016

11. Leach P, Abou-Zeid AH, Kearney T, Davis J, Trainer PJ, Gnanalingham KK: Endoscopic transsphenoidal pituitary surgery: evidence of an operative learning curve. Neurosurgery 67:1205-1212, 2010

12. Meng X, Feng X, Wan J: Endoscopic endonasal transsphenoidal approach for the removal of optochiasmatic cavernoma: case report and literature review. World Neurosurg 106:1053.e11-1053.e14, 2017

13. Mori K, Yamamoto T, Nakao Y, Esaki T: Development of artificial cranial base model with soft tissues for practical education: technical note. Neurosurgery 66 (6 Suppl Operative):339-341, n341, 2010

14. Narayanan V, Narayanan P, Rajagopalan R, Karuppiah R, Rahman ZA, Wormald PJ, et al: Endoscopic skull base training using 3D printed models with pre-existing pathology. Eur Arch Otorhinolaryngol 272:753-757, 2015

15. Okuda T, Yamashita J, Fujita M, Yoshioka H, Tasaki T, Kato A: The chicken egg and skull model of endoscopic endonasal transsphenoidal surgery improves trainee drilling skills. Acta Neurochir (Wien) 156:1403-1407, 2014

16. Prevedello DM, Pinheiro-Neto CD, Fernandez-Miranda JC, Carrau RL, Snyderman CH, Gardner PA, et al: Vidian nerve transposition for endoscopic endonasal middle fossa approaches. Neurosurgery 67 (2 Suppl Operative):478-484, 2010

17. Qureshi T, Chaus F, Fogg L, Dasgupta M, Straus D, Byrne RW: Learning curve for the transsphenoidal endoscopic endonasal approach to pituitary tumors. Br J Neurosurg 30:637-642, 2016

18. Rose AS, Kimbell JS, Webster CE, Harrysson OL, Formeister EJ, Buchman CA: Multi-material 3D models for temporal bone surgical simulation. Ann Otol Rhinol Laryngol 124:528-536, 2015 
19. Shinomiya A, Shindo A, Kawanishi M, Miyake K, Nakamura T, Matubara S, et al: Usefulness of the 3D virtual visualization surgical planning simulation and 3D model for endoscopic endonasal transsphenoidal surgery of pituitary adenoma: technical report and review of literature. Interdiscip Neurosurg 13:13-19, 2018

20. Tai BL, Wang AC, Joseph JR, Wang PI, Sullivan SE, McKean EL, et al: A physical simulator for endoscopic endonasal drilling techniques: technical note. J Neurosurg 124:811-816, 2016

21. Valentine R, Padhye V, Wormald PJ: Management of arterial injury during endoscopic sinus and skull base surgery. Curr Opin Otolaryngol Head Neck Surg 24:170-174, 2016

22. Vescan AD, Snyderman CH, Carrau RL, Mintz A, Gardner P, Branstetter B IV, et al: Vidian canal: analysis and relationship to the internal carotid artery. Laryngoscope 117:13381342, 2007

23. Weinstock P, Rehder R, Prabhu SP, Forbes PW, Roussin CJ, Cohen AR: Creation of a novel simulator for minimally invasive neurosurgery: fusion of 3D printing and special effects. J Neurosurg Pediatr 20:1-9, 2017

24. Wen G, Cong Z, Liu K, Tang C, Zhong C, Li L, et al: A practical 3D printed simulator for endoscopic endonasal transsphenoidal surgery to improve basic operational skills. Childs Nerv Syst 32:1109-1116, 2016
25. Zheng JP, Li CZ, Chen GQ, Song GD, Zhang YZ: Three-dimensional printed skull base simulation for transnasal endoscopic surgical training. World Neurosurg 111:e773-e782, 2018

\section{Disclosures}

The authors report no conflict of interest concerning the materials or methods used in this study or the findings specified in this paper.

\section{Author Contributions}

Conception and design: all authors. Acquisition of data: all authors. Analysis and interpretation of data: all authors. Drafting the article: all authors. Critically revising the article: all authors. Reviewed submitted version of manuscript: all authors. Approved the final version of the manuscript on behalf of all authors: Chen. Statistical analysis: all authors. Administrative/technical/material support: all authors. Study supervision: Chen, Zheng.

\section{Correspondence}

Guo-Qiang Chen: Aviation General Hospital, Beijing, China. guoqchen@mail.tsinghua.edu.cn. 